\title{
Dilemas éticos do lugar da arte contemporânea. Acontecimentos solidários de múltiplas vozes
}

\section{LUIZ GUILHERME VERGARA}

\section{Resumo}

Ao se reconhecer o papel contundente do indivíduo enquanto corpo e voz ativa das multidões na rua, indagamos pelas mudanças em processo no campo das práticas artísticas contemporâneas, identificando um urgente clamor ético para as artes visuais. Percebe-se nestas manifestações um sintoma de esgotamento de uma ordem social da arte regida pela produção de objetos para fruição estética visual que dá lugar ao sentido local e relacional do acontecimento artístico ligado à ativação multissensorial dos corpos onde entrelaçam-se os sentidos de presença e presença dos sentidos. Trataremos nesta abordagem do sentido de presença e temporalidade do corpo e voz como terapêuticas e microgeografias de resistência poética deflagradoras de novos cuidados ético-estéticos com a produção de sentidos públicos da arte nas instituições, museus e bienais.
Palavras-chave:

Arte contemporânea, ética, interações sociais 


\title{
Place as an ethical dilemma in contemporary art. Events of solidarity of multiple voices
}

\section{LUIZ GUILHERME VERGARA}

\begin{abstract}
Drawing a parallel with the rich participation of the individual as both body and voice, now active on the streets of Brazil, this paper explores the changes in process in contemporary artistic practice and identifies an urgent ethical clamor for visual art. From the vantage point of emerging ethical-esthetic practices, the street protests can be seen as symptoms of an exhausted social order. Increasingly we are seeing a body of work emerge that is tired of art ruled by the production of objects and favors the development of a visual aesthetic that gives place to the meaning of the local and the relational artistic event tied to the multi-sensorial activation of the body where the meaning of presence and the presence of meanings are interwoven. The paper examines the meaning of presence and the temporality of body and voice as forms of therapeutic and microgeographic poetic resistance that speak to the emergence of new ethicalaesthetic caring practices for the public meaning of art in institutions, museums and biennials.
\end{abstract}

Keywords: Contemporary art, ethics, social interactions 


\section{Cartografia dos dilemas éticos da arte contemporânea}

1. Corporizações temporais de múltiplas vozes

2. Práticas artísticas contemporâneas - coincidências dos opostos / causalidades reversas entre desterritorialização - reterritorialização;

3. Ética tripartida: convergência entre criatividade; heterogeneidade e solidariedade;

4. Acontecer solidários: lugares do devir

\section{Introdução}

\section{"Nós e não eu" ou "Sai do face"}

Esta apresentação, inicialmente preparada para discutir os dilemas éticos da arte contemporânea enquanto zona de acontecimentos solidários, com o clamor das ruas de junho, foi invadida pela perplexidade, pelo transbordamento ainda maior envolvendo os sentidos macro e micro de geografias de resistências políticas e poéticas que ultrapassam e desafiam o horizonte dos espaços artísticos. A viagem à Escócia em maio e as manifestações nas ruas de junho comprometeram as indagações iniciais que fundamentavam esta reflexão com novas demandas éticas para a arte e educação no mundo contemporâneo. Reconhecemos indissociavelmente um processo global de crise que se amplia criticamente da carência de espaços públicos de interações sociais (sentido de Publicness apresentado por Mick Wilson'1) para os modelos políticos, estéticos e pedagógicos, assim como o retorno contundente 
do debate sobre uma democracia direta alimentada pela participação da sociedade na produção de sentidos.

Entre imagens da multidão e movimentos das massas veiculadas fora das mídias oficiais, se percebe a emergência, ainda que difusa, de um corpo de múltiplas vozes, mas também de vários corpos saídos da invisibilidade das redes sociais em busca de pertencimento presencial nas diretrizes de uma nova ou alternativa ordem social - global. Porém, em especial, esta mobilização coletiva traz consigo uma base ética que rejeita qualquer "voz" de dominação ou de apropriação partidária, e também artística. "Nós e não eu" ou "Sai do face" eram escritos encontrados em muitos cartazes que demarcavam enunciações voltadas a uma democracia direta não pautada pelos padrões de lideranças tradicionais. Não há como estarmos surdos diante destes corpos com vozes.

Resta-nos indagar diante esta virada corporal de vozes coletivas das ruas de junho, sobre os dilemas éticos também do lugar da arte, quando este igualmente não poderá ser regido por parâmetros ou primados da cultura visual, do individualismo, ou de consumismo mercadológico que se atrela a este campo de produção cultural. Como projetar os conceitos de corpo e voz, presença e participação, como parte do resgate simbólico e ético do lugar da arte como laboratório social ou modelo de futuro e de vontade construtiva coletiva?

\section{Incorporações temporais de múltiplas vozes}

Espaço poético - qualquer linguagem a serviço do ético. Lygia Pape, $1975^{2}$

Quem bebe da minha 'caneca' tem sede de liberdade!

Frei Caneca

O que seria este serviço do ético para a linguagem no espaço poético citado por Lygia Pape? Pape é parte de uma geração que fez uma virada fenomenológica existencial para o acontecimento poético, inaugurando um sentido de distância zero entre experiência de criação e recepção, considerando o encontro uma unidade ampliada entre o corpo temporal da obra e os corpos participantes com suas temporalidades. A experiência da obra tomava para si a multiplicação de sentidos e presen- 
zontalmente a galeria em dois níveis de temperatura - quente em baixo do pano e como parte da obra, de um corpo coletivo de várias cabeças ou como Pape projetou: "Já imaginou todas aquelas cabeças sem corpo conversando umas com as outras naquele pano branco?" (MATTAR, 2003, p. 74).

Esta obra nunca foi realizada dentro de uma galeria por questões de recursos, porém ela foi deslocada para um outro cenário - onde a garotada de uma favela pode brincar. Um grande pano de 30x3om com fendas para as cabeças serviu de motivação e surpresa tanto para as crianças quanto para a artista que observou a corrida de todos para participar. Nasce aí um divisor - ou muito mais, um multiplicador ou unificador de corpos e de vozes. Curiosamente, mais uma vez, pela diversidade financeira esta obra se torna muito mais um modelo de futuro do que se tivesse dentro da galeria. O sentido de presença e potência encarna esta obra como um transbordamento coletivo dos parangolés de Oiticica, ou da Cabeça Coletiva de Lygia Clark. Ao ver as manifestações de junho nas ruas revisitamos também esta geração de artistas durante a repressão militar tecendo laboratórios estéticos coletivos para serviços e modelos de inspiração ética.

A imagem da obra de Anish Kapoor no Millenium Park de Chicago ${ }^{3}$ oferece um excelente contraste com a precária escultura de Pape. Porém, ambas podem sugerir uma inspiração ética de unidade de múltiplos corpos. Kapoor, no espetáculo da "nuvem" de superfície espelhada ao mesmo tempo que encarna um oráculo da globalização e o marketing turístico das cidades do século XXI, toma para a obra as presenças passageiras de uma procissão de turistas que são tomados e tomam para si o encontro com a obra. Projetam-se no silêncio de suas câmaras fotográficas as imagens de uma humanidade e diversidade de corpos sobre um corpo universal.

A "nuvem" de Kapoor também remete aos Espaços Imantados de Lygia $\mathrm{Pape}^{4}$, registros urbanos desenvolvidos pela artista a partir dos anos 6o, com o espírito também dos Delírios Ambulatórios na companhia de Oiticica, realizando um inventário de cenas de aglomeramentos das ruas do Rio de Janeiro. Em oposição a grande escultura pública de Kapoor em Chicago, Pape foca nos acontecimentos casuais de encontros urbanos em rodas de capoeira, curandeiros e camelôs. Lygia Pape define os Espaços Imantados a partir de suas andanças pela cidade do Rio de Janeiro, vendo a cidade e seus movimentos como um grande teia de aranha. "O camelô também 
seria uma forma de espaço imantado, no sentido de que ele chega numa esquina, abre aquela malinha e começa a falar, criando de repente uma imantação, com as pessoas todas se aproximando..." Mas Pape vai também para a Baixada e relata os formigueiros humanos - "trata-se de uma poética muito particular, violenta e constrangedora, na sua fúria: a tragédia do homem anônimo, perdido e só" (FUNARTE, 2012, p. 47) 5 .

Ao mesmo tempo, abordamos como dilemas ético-estético da arte contemporânea o que emerge geograficamente como acontecimentos de solidariedades ${ }^{6}$, onde potencializar presenças e processos de subjetivação significa territorializar ações artísticas formando ou ativando corpos em um corpo temporal de múltiplas vozes, de polifonias. Estas reflexões adquiriram um novo grau de complexidade com as grandes manifestações de junho nas ruas de todo o Brasil. Esta apresentação já apontava para o fim do primado das artes visuais, dando lugar ao que apresentamos como microgeografias dos encontros, esculturas caminho (caminhadas coletivas à deriva); proposições artísticas com formatos de aulas e escolas de arte; intervenções coletivas; fóruns; re-ativações ou ocupações de espaços urbanos e terrenos baldios; trabalhos em hospitais e presídios ou acompanhamento de famílias com caso de suicídio ou alzheimer.

\section{Práticas artísticas contemporâneas - coin- cidências dos opostos / causalidades reversas entre desterritorialização - reterritorialização}

\subsection{Zona híbrida - reversibilidade do moderno/pós-moderno/moderno}

A apresentação em Goiânia foi afetada por duas experiências recentes. Primeiramente, a viagem à Escócia (Projeto Fernweh) de pesquisas curatoriais, onde ao se visitar quatro cidades, foram debatidas as relações entre práticas artísticas e a produção de sentido local. A organização desse programa coube à curadora Claudia Zeiske, do Deveron Art em Huntly; Mary Jane Jacob, Chicago, e Nuno Sacramento, diretor e curador do SSW (Social Sculpture Workshop, Lumsden, Escócia). Em segundo lugar, e talvez mais contundente ainda, se refere à própria semana de 11 de junho, ocasião também do encontro de Goiânia, quando eclodiram as manifestações das grandes multidões nas principais cidades do Brasil. 
Figura 3 Jacqueline Donachie, Slow Down. Fotos: Alan Dimmick

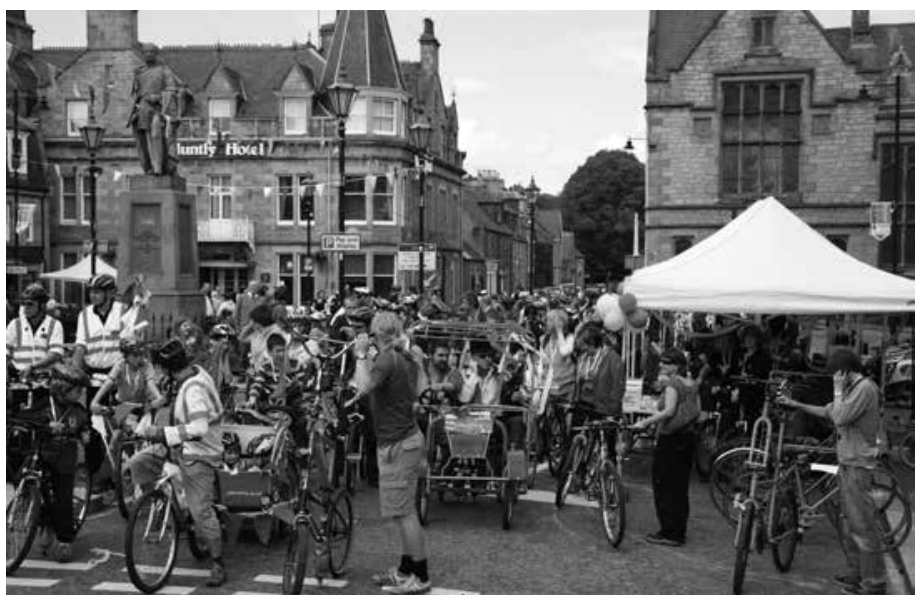

Figura 4

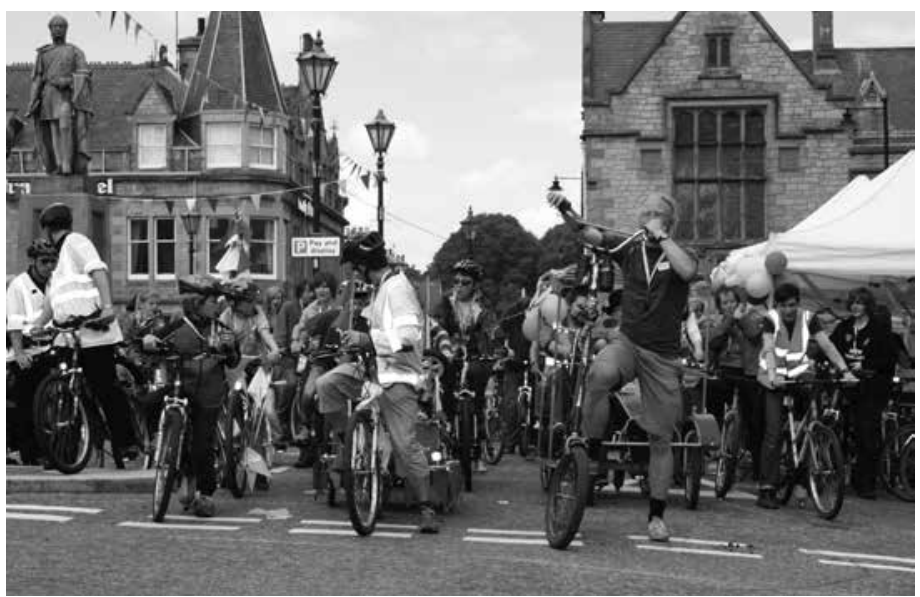

Estamos diante de uma fratura através da qual se coloca em cheque não apenas o primado ou glamour das estéticas visuais para uma direção não ainda consciente ou definida, mas também os cuidados com as demandas ético-estético da arte contemporânea na sua reconfiguração enquanto esfera pública de interações sociais. Ao se considerar os cuidados com estas mudanças apontamos para a singularidade e complexidade das interações participativas e afetivas quando instituídas e não instituintes de novos parâmetros curatoriais, estéticos e pedagógicos. Nesta ordem emergente de temporalidades e territorialidades apresentamos os horizontes de potência e resistência poética dentro de microgeografia dos vínculos relacionais e contextuais que exige também mudanças nas 


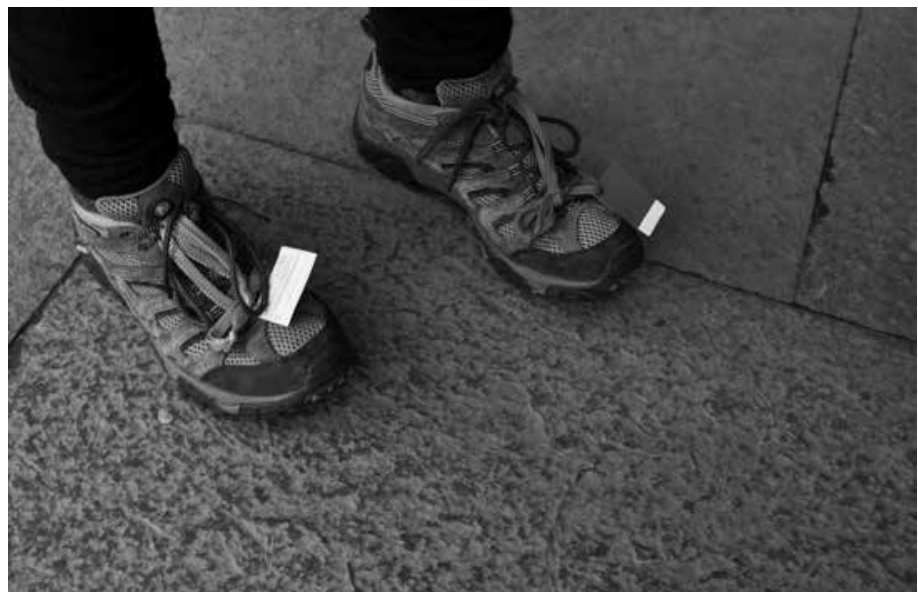

políticas e práticas curatoriais e pedagógicas das instituições públicas da arte (museus e instituições públicas).

Desde os anos 60 já se falava de territórios de resistência e vivências coletivas, porém o que se coloca nesta abordagem diz respeito ao cuidado com as práticas conceituais que avançam para a ativação de espaços críticos de acontecimentos participativos e solidários. Ao mesmo tempo em que ainda se busca uma contundência e ruptura de modelos formalistas da produção artística, multiplicam-se no cenário contemporâneo os processos relacionais de desmaterialização da formaobjeto artístico. Mesmo assim, ainda convivemos com a complexa justaposição de valores opostos entre objeto-processo / processoobjeto, principalmente nos acontecimentos de grande escala cultural, tais como bienais e museus. Podemos reconhecer a resistência poética da arte convivendo com a sua institucionalização ou espetacularização, a macro com uma microgeografia de acontecimentos solidários. Abordaremos esta condição provocando o conceito de reversibilidade contemporânea (moderno / pós-moderno) pela justaposição desses sentidos opostos. O lugar paradoxal e suspenso da arte é sempre ativador também de suas próprias contradições.

Esta situação crítica, ou zona híbrida, é regida, para além dos sentidos históricos, e tomada pelo mercado do glamour e fetiche da espetacularização, mas também toma para si o desafio da resistência poética do experimental. Este é também o lugar de uma crescente busca levantada pela produção de vínculos locais na (re)territorialização e experiência compartilhada de sentidos. Simultaneamente reconhecemos 
esta zona híbrida sendo debatida por vários críticos e filósofos - porém que ainda mantém uma abordagem regida pela dicotomia das fronteiras entre uma estética do sublime como Rancièrre $^{7}$ apresenta, impulsionada pelo princípio de ruptura crítica com valores estabelecidos. Do outro lado, estariam os processos ligados a uma virada social, ou se alinhando com as estéticas relacionais de Nicholas Bourriaud. Nos interessa trazer o conceito de justaposição e reversibilidade de opostos para esta zona híbrida onde a (re)territorialização enquanto prática curatorial, artística e pedagógica exige um cuidado com as interações sociais, a formação de novos narradores e narrativas, esculturas sociais de agenciamentos de subjetivação e afetos. Rancière apresenta essas duas forças ou impulsos estéticos opostos enquanto utopias estéticas. Por um lado, a estética do sublime voltada à potencia do intangível, mantém sempre uma distância entre uma ideia e o sensível. A estética relacional, ainda na abordagem de Rancière, institui a presença, forma comunidades, invoca uma nova modéstia para as ambições de ruptura da arte:

criando situações aptas a modificar nosso olhar e nossas atitudes a respeito deste ambiente coletivo. Tais micro-situações, que variam minimamente daquelas da vida ordinária e são apresentadas mais de uma forma irônica e lúdica do que critica e denunciadora, buscam criar ou re-criar elos entre indivíduos, para oferecer novos modos de confronto e participação (RANCIÈRE, 2009, p.21).

Interessa-nos apresentar esta reversibilidade entre duas utopias estéticas que alimentam o lugar paradoxal da arte quando abordadas como geografias da arte para uma condição contemporânea globalizada. Preocupações com a contextualização da produção de sentidos não excluem os exercícios de ruptura e liberdade, porém sob uma perspectiva crítica com relação às ambições modernistas de choque e ruptura missionária da arte. Observamos as últimas bienais de São Paulo e toda a trajetória da Bienal do MERCOSUL como macro e microgeografias de resistência poética onde as curadorias absorvem para si a responsabilidade ética e pedagógica como parte extensiva e reversível entre objetos-processos de interações sociais. O que também se reflete nas pequenas aldeias da Escócia ou nos debates sobre o programa Cadernos de Viagem da 8aㅡ Bienal do MERCOSUL - Geopoética. 


\subsection{Práticas artísticas contemporâneas - causalidades reversas entre desterritorializa- ção - reterritorialização}

\section{Experiência - Fernweh x Vinculo / Escócia 2013}

Tratamos na viagem à Escócia de indagações críticas sobre o sentido do lugar da arte em pequenas cidades ou comunidades remotas, enquanto esfera de trânsitos poéticos de artistas viajantes, ou territórios suspensos por uma produção estética pautada pelo estranhamento, ou desterritorialização. O debate que acompanhou esta viagem era ligado às fronteiras entre uma expectativa de uma experiência estética sublime ou relacional. Como quebrar esta dicotomia entre potência estética "sublime", esta conduzida pelo impacto de uma forma missionária ou revolucionária modernista sobre uma sensibilidade local, e uma produção artística relacional engajada e contextualizada com as percepções e participações locais? Se reconhece, ainda, uma atitude artística romântica - viajante, que ativa pelo choque e ruptura os valores artísticos instituídos historicamente, provocadora de acontecimentos ou eclosão formal de uma razão nomádica - desterritorializada. Por outro lado, a ruptura contemporânea poderia agora estar sendo lançada por um campo de relações coletivas, corporais, afetivas e presenciais, sem o fetiche da forma sublime - intangível.

Curiosamente, Fernweh - palavra germânica que significa o oposto à saudade de casa, ou como apego à condição de viajante, também serviu para apresentar um conjunto de propostas artísticas na Escócia, tais como o programa Deveron Arts de residência internacional que explora a cidade de Huntly (de apenas 4 mil habitantes) como suporte para intervenções urbanas com a participação social. Paradoxalmente, este termo alemão trouxe para a visita à Escócia a referência ao espírito que se apega à viagem, ao risco e desconhecido, em oposição à condição instituída e sedentária. Se por um lado fernweh poderia ser um princípio presente no romantismo explorador de novos horizontes, talvez ainda ligado ao artista viajante que se entrega a uma razão nomádica. Este impulso também missionário e peregrino modernista atraído pelo desconhecido e estranho foi contraposto pelo sentido de cuidado ou vínculo com as comunidades locais. Apontamos para uma situação de contrapontos para se pensar o lugar da arte contemporânea enquanto utopia concreta 

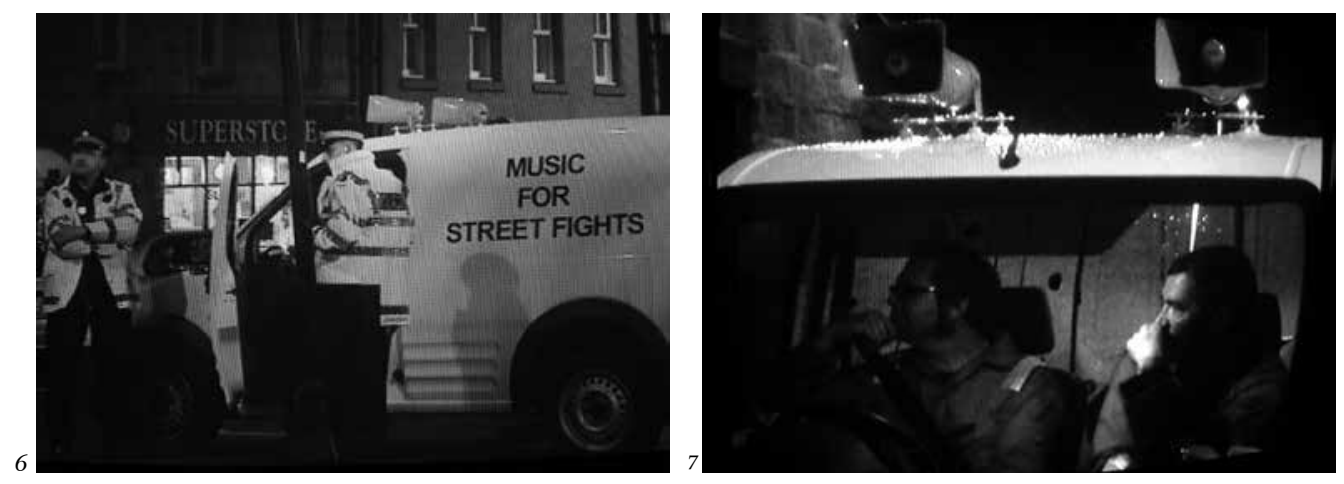

Figura 6, 7 e 8 Gary Williams, Música para brigas de rua. Foto: Jelka Plate

indissociável de sua contextualização geográfica. Nesta abordagem se justapõe uma ética do cuidado ou teoria de vínculo ${ }^{8}$ com a estética do sublime ou uma estética relacional que não desqualifica a intervenção e potência de agir artístico.

As complexidades que diferenciam e aproximam a utopia estética ligada ao sublime e uma outra, engajada e relacional, que demanda cuidados com o vínculo ou contextualização territorial e temporal dos discursos artísticos contemporâneos foram foco dos debates realizados durante uma semana de encontros na Escócia, que cabem perfeitamente para os horizontes de possibilidades e diversidades brasileiras.

How can art production be 'meaningful'to the social, geographical and historical context of Helmsdale? How do socially engaged art practices and galleries fit together?

Como a produção artística pode ser significativa para o contexto social, geográfico e histórico de Helmsdale? Esta questão foi colocada em debate na cidade de Helmsdale pela curadora do Centro e Museu da História Local e Galeria de Arte Contemporânea - "Time Span" - lugar de encontro entre nosso passado e nosso Futuro (Meeting place between Our past E Our Future).

Uma outra questão colocada foi "Como as práticas artísticas socialmente engajadas e as exposições em galerias podem se ajustar mutuamente?"

Essas perguntas são completamente apropriadas tanto para um debate na Escócia, como em Chicago e também no Brasil, seja em Goiânia ou nas várias regiões e estados brasileiros. O que vale também para os projetos curatoriais e educativos das grandes bienais e museus, como também para os projetos artísticos nas periferias do Rio, tais como o projeto Travessias na favela da Maré ou no MAC de Niterói.

Claudia Zeiske e Nuno Sacramento elaboraram um roteiro de visitas a quatro centros de produção artística na Escócia 


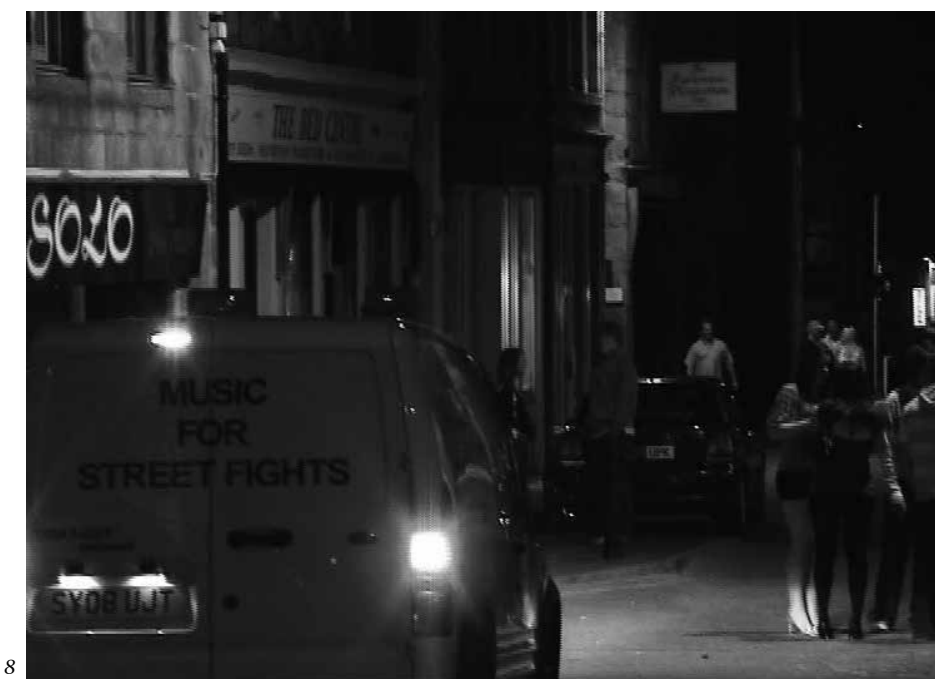

em abril/maio de 2013, apresentando em diferentes cenários uma preocupação clara de se investir em práticas artísticas conceituais voltadas à construção de sentidos locais.

Cruzando a Escócia de trem de nordeste a noroeste foram visitadas quatro organizações com foco em práticas artísticas públicas e comunitárias, se iniciando em Huntly, com Deveron Art, incluindo a SSW em Lumsden, Timespan em Helmsdale, ATLAS em Skye, IOTA em Inverness. Nesta viagem os tópicos discutidos foram:

1. Conversa + Diálogo

2. Comunidade + Lugar

3. Viagem + Remoto (longínquo)

4. Urbano + Diálogos Rurais

Os tópicos críticos escolhidos para esse projeto identificam os dilemas éticos contemporâneos para uma zona híbrida que ultrapassa o primado visual e clama para a validação do presencial, do cuidado com as práticas sociais, com o aprofundamento de vínculos, com os afetos e processos de subjetivação. Nestas tendências, ao mesmo tempo que se observa uma fragilidade crítica entre parâmetros tangíveis e intangíveis, também se reforça um processo histórico da eclosão nuclear da crença no objeto da arte isoladamente do seu contexto.

Neste sentido os dilemas ético-estéticos estão presentes nos cuidados e vínculos que envolvem as intervenções ambientais, ações urbanas e práticas coletivas quando voltadas aos empoderamentos relacionais ou presenciais. Esta fissura ou desmaterialização nuclear da forma artística que dá lugar a processos 
participativos invocam um sentido de corpo e territorialização dentro de uma razão sistêmica e política da arte com lentes macro (globais) e microgeográficas locais. $\mathrm{O}$ que entra em jogo também é a reconfiguração das formas e práticas da arte indissociáveis das políticas curatoriais e pedagógicas das instituições públicas. É justamente nesta zona de transfigurações entre forma e processo que se apresenta o resgate simbólico do corpo como campo de múltiplas vozes como acontecimento solidário envolvendo o princípio de afeto espinosiano ${ }^{9}$ como microgeografia de resistência poética ou como também abordaremos como terapêutica antropofágica (Oswald de Andrade) ${ }^{10}$.

Exploramos pelas lentes da microgeografia ainda uma utopia concreta de resistência poética com foco nos acontecimentos de solidariedade ou territorialização de devires compartilhados nas práticas artísticas contemporâneas. Ao mesmo tempo, apontamos para o transbordamento e reversibilidade das fronteiras entre as artes visuais e o surgimento do sentido de presença como parte de uma consciência e ativação política institucional e poética como dimensão ética de um corpo individual e coletivo, público e privado, de enunciação e escuta de múltiplas vozes. Enquando uma zona híbrida de objeto e processos, em vários casos elas partem de uma reversão que simultaneamente se realiza enquanto acontecimento inaugural de estranhamentos ou desterritorialização e reterritorialização do fenômeno artístico, justapondo uma estética da rupturas nomádicas ou do sublime por uma prática e busca de vínculos ${ }^{11}$.

Abordamos estas dicotomias através da imagem de um exercício pendular de reversibilidades entre o dentro e fora da instituição museu, ou objeto - processos, reivindicando uma escala presencial e corporal de afetos no sentido espinosiano isto é, geradores de potência de agir. É deste resgate de Espinosa (ainda através de Deleuze e pesquisadores da saúde ${ }^{12}$ ) que trazemos também uma dimensão ética, juntamente com a geográfica e terapêutica, buscando abordar também seu potencial de resistência como ativadora (poética) de múltiplas vozes e temporalidades. A complexidade deste debate foi também abordado através dos registros do seminário internacional Reconfigurações do público: arte, participação e pedagogia (acontecido no MAM, no Rio de Janeiro em 2011), motivado também pela necessidade de se investir ou adensar o campo de pesquisas e ações ampliadas sobre as zonas-limites da esfera pública da arte e cidadania ${ }^{13}$.

Como explorar estas mudanças como complexidade indissociável entre ético-estético, forma e processo, objeto de criatividade-liberdade e rede de heterogeneidade-solidarie- 
dades? Esta indagação é parte inacabada da virada das utopias modernistas para o fenômeno artístico no mundo globalizado pós-moderno. Defendemos, no entanto uma microgeografia de resistência poiética, onde os cuidados com a produção de sentido são qualificações do espaço de subjetivações, heterogeneidade e territorialidade dos corpos em interfaces com o campo de acontecimentos artísticos. Isto é, como fenomenologia das presenças que cuida do sentido da experiência na experiência dos sentidos, conjugando a territorialização da arte com um território de diversidade da esfera pública. A arte se coloca a serviço do ético como prática de resistência quando cuida da gestão de afetos - potências de agir dentro das múltiplas temporalidades.

\section{3. Ética tripartida: convergência entre criatividade; heterogeneidade e solidariedade}

Os acontecimentos de junho chamam a atenção para a dimensão tripartida destas manifestações de rua como uma onda convergente de criatividade - heterogeneidade - solidariedade. Até hoje não se tem uma causalidade determinante, mas sim, um futuro que reverte o presente como eclosão paradoxal. É preciso ainda não perder o seu horizonte simbólico, crítico e transformador como causalidade reversa do evento de desterritorialização das ordens existentes. Fred Evans ${ }^{14}$ explora a partir do pós-modernismo e o conceito de globalização de baixo para cima (grassroots globalization) a conceituação de uma solidariedade da diferença. A criatividade nestas manifestações estaria posta numa direção emergente da prática das redes de heterogenidades e diferenciações, o que muito bem encarna a proposição de Evans para um corpo de múltiplas vozes. Daí citando atores como Deleuze; Guattari; Foucault; Hardt; Negri e Castells, Evans trabalha em uma perspectiva que quebra dicotomias entre noções axiomáticas e nomádicas; império e multitudões. Evans reinterpreta estas polaridades em termos de vozes em oposição aos oráculos para superar os problemas contemporâneos dos anonimatos e as instituições mediadores dominantes. A ideia de solidariedade proposta não é ortodoxa, mas sim de uma sociedade da diferença, como práticas em redes que incorporam ou encarnam um corpo - acontecimento de múltiplas vozes. Esta é uma questão que fica evidente nas manifestações das ruas. Porém, o acontecimento ou desterritorialização somente não basta. Ele deve ser gerador de uma reconfiguração ou metamorfose contínua da esfera pública ou social. 
Pode-se perguntar ainda pelo sentido do lugar da arte nestes acontecimentos - enquanto instituídos como oráculos ou como rupturas decorrentes da razão nomádica? Porém, para que a arte não perca suas lentes microgeográficas de resistência poiética há que se ressignificar como parte dos acontecimentos solidários locais. Neste sentido, um viés de reversibilidade causal é trazido para a responsabilidade da arte enquanto contraponto crítico à sua própria absorção pelo mercado e instituições como fetiche e oráculos. A vitalidade da arte é paradoxal como estrutura viva - nômade dentro e fora das instituições culturais, onde toda a ação é reflexivamente crítica (desterritorializada) e reconfiguradora de vínculos e hierarquias que regem as práticas curatoriais - artísticas e pedagógicas.

Ainda retomando as manifestações das multidões nas ruas, cabe resgatar Deleuze e Guattari e o sentido de territorialização a partir de dois fluxos opostos - nas "máquinas nomádicas de guerra" que encarnam as forças e acontecimentos de ruptura e desterritorialização. E o Estado seria um campo gravitacional oposto, um contra-fluxo ou aparato de "reterritorializacão". Do interplay entre estes movimentos de causalidades reversas se reconhece a emergência do devir - do "become" como potência que Deleuze e Guattari atribuem à arte, conjugando desterritorialização e reterritorialização. A reversibilidade entre estes sentidos relacionais e sublime é colocada como quebra da ordem do tempo, o acontecimento da territorialização antecipa o futuro no presente como emergência do devir (become). Com a conceituação de Deleuze para "causalidades reversas ${ }^{15}$ " - procuramos abordar o acontecimento do porvir e transformação da arte pela territorialização, conjugando simultaneamente o evento como eclosão do futuro sobre o presente, e este como ressignificação do passado, de forma a subverter o sentido de tempo.

Physics and biology present us with reverse causalities that are without finality but testify nonetheless to an action of the future on the present, or of the present on the past, for example, the convergent wave and the antecipated potential, which imply an inversion of time ${ }^{16}$.

Esta é uma questão também globalizada - que se traduz com a pergunta feita na Escócia para um encontro de curadores: como a arte pode ser vista como um acontecimento de produção de sentidos locais, geográficos, históricos e sociais - e, ao mesmo tempo, sem perder sua potência de rupturas, de estranhamentos e desterritorializações suspensas em estéticas globais? 
Desta ativação geográfica e pública das presenças de multidões e múltiplos corpos e vozes nas ruas projeta-se uma indagação sobre as ações estéticas contemporâneas além da arte. O clamor das ruas invade com demandas éticas o compromisso da arte com as interações sociais - com uma unidade ética tripartida da criatividade, heterogeneidade e solidariedade. Como elas poderão afetar as próprias hierarquias e saberes que dirigem e para quem dirigem as instituições públicas da arte? A própria conceituação da arte como acontecimento traz para si o compromisso com uma solidariedade indissociável do exercício da liberdade; da criatividade para reverter heterogeneidade - diversidade em corpo de múltiplas vozes.

Joseph Beuys também traz uma confluência ética para a criatividade e as interações sociais.

O conceito de liberdade tem dois aspectos: o primeiro diz respeito ao individual, aquele que é livre para fazer o que lhe agrada; o segundo, o mais importante, tem haver com as relações interpessoais ( o que significa compartilhar os frutos das ações livres) ${ }^{17}$.

É da utopia concreta de Beuys (entre outros) que ampliamos este recorte paradoxal diante do clamor das ruas de junho por uma nova ordem para ativar o sistema da arte, como geografia de resistência e terapêutica poética diante à sociedade controlada e dominada pela competição, individualismo e consumo de produtos. Este fluxo global de demandas éticas confronta o primado de diretrizes neoliberais que dominam os produtos da economia criativa em todas as suas ramificações de práticas públicas - privadas, tanto da arte como da educação, alimentando, de forma subliminar, uma apologia e pedagogia da criatividade que se corrompe pela competição e produção de imagens de consumo e sucesso individual. Ao mesmo tempo que se questionam tantas hierarquias corruptas, também devem ser revistas as dicotomias conservadoras do mundo da arte compartimentando a sociedade entre criadores e espectadores, os espíritos livres, iluminados, gênios e os subalternos.

\section{Acontecer solidários: lugares do devir}

Revisitando o conceito de corpo de Espinosa através da abordagem de Ricardo Teixeira ${ }^{18}$ convergimos um conceito de saúde a partir dos postulados da ética de Espinosa, para uma invocação à temporalidade presencial do corpo-voz e afeto-alegria como 
transversalidade para a conceituação de terapêutica dos acontecimentos de solidariedade na arte contemporânea dentro e fora de suas instituições (museus, escolas e espaços públicos).

1. O Corpo humano, como um acontecimento de encontros, assim como as estéticas de afecções coletivas (exemplo: museus - escolas - intervenções) se compõe de muitíssimos indivíduos (de diversa natureza), cada um dos quais é um composto.

2. Os indivíduos que compõem o corpo humano e, por conseguinte, o próprio corpo humano, são afetados de muitíssimas maneiras pelos corpos exteriores.

…

3. O corpo humano necessita para conservar-se, de muitíssimos outros corpos, eé como se esses o regenerassem continuamente ${ }^{19}$.

A microgeografia dos corpos de múltiplas vozes transpassa as práticas artísticas que enfocamos (dentro ou fora dos museus ou bienais). Estas se realizam como incorporações temporais de uma consciência do corpo coletivo público, revendo potência estética não pelo primado da percepção visual, mas pela sua pulsação catalisadora de vontade e vozes de construção coletiva e desejo de afecções diretamente ligadas e alimentadas pela participação e presença social.

Concluímos esta meditação necessária que aponta também a passagem ou dobradura entre moderno e contemporâneo revertendo causalidades desde o programa ético ambiental de Oiticica para um "serviço do ético" de Lygia Pape. Afirma-se, no entanto, como diferencial ético uma convergência tripartida entre criatividade, heterogeneidade e solidariedade (EVANS). Porém, é justamente com as eclosões crescentes de manifestações de ruas reunindo multidões de corpos e vozes, que trazemos o sentido de subversão do futuro no presente pelas causalidades reversas. Neste mesmo sentido, o conceito de quiasma de Merleau-Ponty ${ }^{20}$, ou na ética de Espinosa, estas ocorrências encarnam modelos e modelagem fusão temporal de corpos e vozes em territórios políticos, estéticos e existenciais.

O acontecer memorável e solidário proposto por Milton Santos é corporificado em novas tendências da arte mais alinhadas como virada social ou estéticas relacionais, como nas obras do Coral de queixas, de Oskar Koshta ${ }^{21}$, como parte dos Cadernos de Viagem da 8 a Bienal do Mercosul, ou como vimos no "Divisor" de Lygia Pape, ou ainda nas proposições 


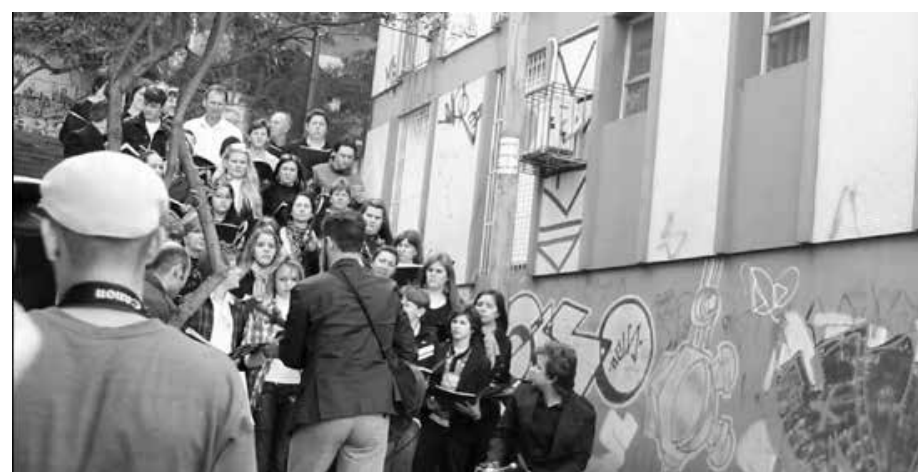

relacionais de Deveron Art na Escócia. Em diferentes escalas estas propostas se apropriam dos fluxos humanos na inauguração de espaços imantados, dentro e fora das instituições.

Porém, cabe ainda ressaltar a busca do sentido da arte enquanto espaço poético a serviço do ético. $\mathrm{O}$ acontecimento solidário aponta também para estruturas ou esculturas vivas de entrelaçamento ou quiasma de Merleau-Ponty ${ }^{22}$. Como dimensão fenomenológica rompe-se a exterioridade entre indivíduos e ambiente que experimentam a realização da escultura - como tecer e tecido, tais como, parangolés e penetráveis de Oiticica, na procissão do "Divisor" da Lygia Pape, ou na escultura de vozes coletivas de Oliver Koshta. Em todos esses casos o acontecer é solidário, quando cada indivíduo toma para si a participação no corpo da obra e na medida que esse corpos coletivos se realizam reciprocamente, o ser é tomado para a existência e pertencimento da obra. Nesta escala múltipla de microgeografia, esta experiência é também do que Ponty reflete como Ser da Humanidade e o Ser da linguagem, os acontecimentos do futuro que vêm se dando através do corpo a corpo na presença de múltiplas vozes.

Justapomos a virada da arte centrada em dicotomias entre objetos-sujeitos, espetáculos-espectadores, para sua abertura enquanto campo de interações ambientais e entrelaçamentos existenciais. Esta proposição de dobras e desdobras, ou reversibilidades causais, implicam no cuidado temporal das relações e interações sociais que se traduzem na noção de laboratório público de afetos e potência de agir do encontro e corpo de Espinosa, resgatado por Deleuze. Aplica-se aí o resgate de uma ética espinosiana centrada nas relações entre corpo, cuidado e afeto. Nesses apontamentos e notas, identificamos também um pragmatismo qualitativo para a vida pública da arte como território de criatividade, heterogeneidade e solidariedade que remete também para a vontade construtiva
Figura 9

Imagens da Bienal Mercosul Coral de Queixas 
Figura 10 Bate Papo na Cama MAC de Niterói

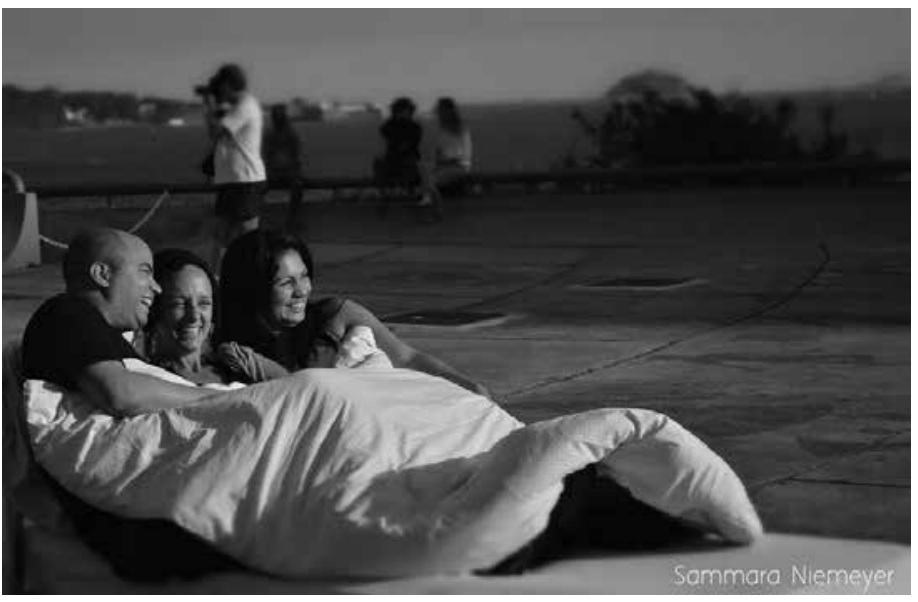

coletiva como nova objetividade de Oiticica (HO, Esquema Geral da Nova Objetividade, 1964) a ser atualizada como produção de novas subjetividades e alegrias como potência de agir.

O acontecer solidário atualiza para o contemporâneo o que Merleau Ponty nos últimos anos de sua vida atribuiu aos sentidos no processo de mutação na relação entre humanidade e Ser, que está em andamento na nossa época. A própria prática ambiental da arte encarna a experiência dos sentidos (feeling), tomados como um corpo emocional, indivisível do intelectual, da mesma forma que o coletivo é do individual.

Com a centralidade relacional entre pertencimentos mútuos - sujeito-corpo e mundo, o devir ou futuro da arte vem se manifestando no tempo presente seguindo as suas bases fenomenológicas existenciais. Cumpre-se também um crédito à noção de quiasma - entrelaçamento de Ponty. O acontecimento artístico realiza o espaço poético como prática e serviço do ético, dispondo ao sujeito o horizonte (futuro) de seu pertencimento à humanidade. Todo ato criador é multiplicador de vontades coletivas - da liberdade de tomar e ser tomado pelo corpo, escultura e tecido social: "toda relação com um sujeito Ser - é simultaneamente a de tomar e ser tomado, o sujeito que toma é ao mesmo tempo objeto tomado, é inscrito e inscreve no mesmo Ser - sujeito - que realiza a ação".

Existe um risco em trazer conceitos tais como terapêutica e "afetos" para se projetar um documento sobre dilemas éticos ou críticos institucionais da arte contemporânea. De imediato a palavra afeto traz um sentido de fragilidade emocional. Precisamos dar uma outra densidade a este conceito a partir de Espinosa para reconfigurar a vida pública da arte e de seus abrigos, os 
museus (ou dos espaços culturais públicos). A experiência dos acontecimentos (com ou sem arte) contemporâneos deflagram microgeografias e temporalidades causais de uma "unidade intersetorial de um mundo dinâmico" e fluido que alimenta e encarna a visão de um corpo coletivo instituinte e vivo formado por vários corpos que se afetam e se transformam mutuamente. A ideia de terapêutica antropofágica de Oswald de Andrade aponta para este futuro e presente, presença e entrelaçamento de corpos de múltiplas vozes e afetos que nos faz pensar também na responsabilidade e cuidados desses espaços públicos de resistência, ativações e pulsações coletivas do devir.

\section{Referências}

ANDRADE, Oswald de. A marcha das utopias [1953], in A Utopia Antropofágica, Obras Completas de Oswald de Andrade. Globo, São Paulo, 1990.

DURINI, Lucrezia De Domizio. The felt Hat. Joseph Beuys. A life told. Italy: Edizioni Charta, 1991.

EVANS, Fred. The Multivoiced Body. Society and communication in the age of diversity. New York, 2009.

FUNARTE, Rio de Janeiro. Lygia Pape, São Paulo: Pinacoteca do Estado de São Paulo, 2012.

GUATTARI, Félix. A thousand plateaus. Capitalism and schizophrenia. Minneapolis: The University of Minnesota, 2003.

MATTAR, Denise. Lygia Pape. Rio de Janeiro: Relume Dumará, 2003.

MERLEAU-PONTY, Maurice. O Visivel e o Invisivel. São Paulo: Debates - Editora Perspectiva, 1992.

PARKINSON, G. H. R. (org.). Spinoza Ethics. New York: Oxford University Press, 2003.

RANCIÈRE, Jacques. Aesthetics and Its Discontents. Cambridge: Polity Press, 2009.

ROLNIK, Suely. Subjetividade Antropofágica. In: HERKENHOFF, Paulo e PEDROSA, Adriano (org.). Arte contemporânea brasileira: um e/entre Outro/s. São Paulo: Fundação Bienal de São Paulo, 1998, p. 128-147.

SOUZA, Maria Adélia Aparecida. Território usado, espaço banal, espaço de todos. Elementos da obra de Milton Santos para um diálogo com a Geopoética. Texto elaborado para a Sessão Geopolítca/geopoética, do Seminário Internacional Ensaios de Geopoética, organizado na 8a Bienal do Mercosul, realizado em Porto Alegre, 10 de setembro de 2011.

TEIXEIRA, Ricardo. A grande saúde. Interface. Comunicação Educação e Saúde. Vol. 8, n. 14. P. 35-72. Setembro 2003 - fevereiro 2004. 
TORRES, Ruslán. Investigación, Arte y Experiencia 2001-2007. L.CONDUCT-A-RT Taller de Arte y Experiencia. La Habana: Faculdad de Artes Plásticas Instituto Superior de Arte, 2007.

NOTAS

1. Texto apresentado por Mick Wilson no Seminário Internacional - Reconfigurações do Público: arte, pedagogia e participação. Ensaios e vídeos das mesas redondas do seminário Reconfigurações do publico: arte, pedagogia e participação são disponibilizados: www.seminario.mamrio.org.br

2. Citação de Lygia Pape. Ver MATTAR (2003).

3. Fred Evans explora o Millenium Park como indagação crítica sobre a democracia e cidadania da arte pública em ¿Voces de la democracia?: ciudadanía y arte público en el Millennium Park de Chicago. Por ejemplo, los críticos sostienen que el Millennium Park de Chicago, subvencionado en gran parte por las corporaciones, "naturaliza" los intereses del capital y reduce el arte público al estatus de "espectáculo" o de estética "wow". Aunque esta critica es convincente, argumento que un análisis cuidadoso del Millennium Park sugiere que debemos ver el parque compartiendo una estructura similar a la sociedad en paradójica entre el espectáculo y una "estética relacional" que sí misma - lo que llamo "un cuerpo de múltiples voces" o "un cuerpo dialógico" - y sus obras de arte como ejemplos de una relación prioriza los efectos de los objetos de arte en las relaciones entre sus espectadores y los efectos de los espectadores en los objetos de arte.

4. Ver Mattar (2003, p. 87)

5. Ver também (p. 285). In. Catálogo: Lygia Pape Espaço Imantado. São Paulo: Pinacoteca do Estado de São Paulo, 2012.

6. Acontecer solidário de Milton Santos. Milton Santos vai relacionar o lugar ao mundo e defini-lo como um "espaço do acontecer solidário". Ver Souza (2011).

7. Ver Rancière (2009).

8. Ruslán Torres apresenta a Teoria del Vínculo de Enrique Pichon Rivière como um dos princípios que mobilizam seu Taller de Arte y Experiência em L.Conduct-A-RT. Ver Torres (2007).

9. Ressalta-se a proximidade corporal como dimensão ética no sentido das afecções e afetos de Espinosa como qualificação de um encontro pela sua potência geradora de vontade reflexiva e expansiva de agir, ou também como motivação afirmativa. Ver Parkinson (2003).

10. Resgata-se neste debate uma crítica cultural presente desde o Manifesto moderno de Oswald de Andrade em 1922, para "o espírito que se recusa a conceber o espírito sem o corpo", se alinhando com uma "terapêutica social para o mundo contemporâneo". Suely Rolnik desenvolve a idéia de "Combater a baixa antropofagia e afirmar o modo antropofágico de subjetivação em seu vetor ético é uma responsabilidade que temos não só em escala nacional, mas também e, sobretudo, em escala global, pois livrar-se do princípio identitário-figurativo é uma urgência que se faz sentir por todo o planeta. Somos portadores da fórmula de uma vacina que permite resistir a este vício: a "vacina antropofágica", como a designa um dos Manifestos22, prescrita para "o espírito que se recusa a conceber o espírito sem o corpo". De fato, a vacina antropofágica parece ter se tornado indispensável para uma ecologia da alma (ou do desejo?) neste início de milênio. Rolnik, em seu texto "Subjetividade Antropofágica" (1998, p. 128147) se apoia em Oswald "que chegou a defender a tese de que a Antropofagia constituiria uma "terapêutica social para o mundo contemporaneo". 
11. Ruslán Torres aplica a Teoria del Vínculo de Enrique Pichon Rivière como um dos princípios que mobilizam seu Taller de Arte y Experiência em L.Conduct-A-RT.

12. Ricardo Teixeira traz a questão do corpo em Spinoza através da releitura de Deleuze, porém para refletir sobre saúde pública.

13. Ensaios e vídeos das mesas redondas do seminário Reconfigurações do publico: arte, pedagogia e participação são disponibilizados: www.seminario. mamrio.org.br

14. Fred Evans no capítulo Globalization, Resistance, and the new solidarity (p.243).

15. Fred Evans explora o conceito de reversibilidade causal de Deleuze e Guattari. Uma ação do futuro sobre o presente. Esta reversibilidade causal pode ser oportunamente trazida para os eventos das manifestações das ruas de junho, sem que se reduzam aos apelos pelos 20 centavos de passe livre do transporte.

16. Ver Reverse Causality em DELEUZE e GUATTARI (2003).

17. Joseph Beuys. The following seven points regarding the fundamental terms of creativity represent the artist's approach to the social problems of man, and to relationships in the fields of economics and education. Ver Durin (1991).

18. Ver Teixeira (2004).

19. Ibid.

20. Merleau-Ponty dedica um capítulo especial para o conceito de Quiasma - Entrelaçamento. Estes dois termos são usados como recursos metafóricos para apresentar os desafios da reflexão e indagação filosófica, como dobradura (entrelaçamento) entre instrumento de comunicação, criação e expressão, daquilo que é indizível, invisível, que tanto pela arte, poesia e filosofia, tomam forma visível e encarnada na existência humana.

21. O projeto Coral das Queixas do artista finlandês, Oliver Koshta, inaugurado anteriormente em outras cidades vários anos atrás, foi proposto como projeto para Teotônia, uma pequena cidade do interior gaúcho, famosa por possuir 100 corais.

22. Ibid.

Recebido em: 02/10/2013

Aceito em: 02/11/2013

\section{LUIZ GUILHERME VERGARA}

\section{luizguivergara@gmail.com}

Doutor em Arte e Educação pela Universidade de Nova Iorque (NYU) e Professor do Departamento de Arte e Mestrado em Estudos Contemporâneos da Arte da Universidade Federal Fluminense (UFF). Atual curador do Museu de Arte Contemporânea (MAC) de Niterói, onde já atuou como diretor da divisão de educação (1996-2005) e diretor geral (2005-2008). Coordenou (abril 2012) o Núcleo Experimental de Educação e Arte do MAM Rio de Janeiro e é co-fundador do Instituto MESA: Mediações Encontros Sociedade e Arte. 